\title{
Correction to: Chitooligosaccharides from squid pen prepared using different enzymes: characteristics and the effect on quality of surimi gel during refrigerated storage
}

Avtar Singh', Soottawat Benjakul ${ }^{1 *}$ and Thummanoon Prodpran ${ }^{2}$

Correction to: Food Production, Processing and Nutrition (2019) 1:5

https://doi.org/10.1186/s43014-019-0005-4

In the original publication of this article (Singh et al. 2019), the author point out the '3.18-4.77 CFU/g' in sentence 'At day 10, all counts were in the range of 5.49-6.57 and 3.18-4.77 CFU/g sample for gels added without and with COS-L' should be '3.18-4.77 log CFU/g'.

In Table 3, the unit of Microbial load "(CFU/g)" should be corrected as "(log CFU/g)"

The original publication has been corrected.

\footnotetext{
Author details

'Department of Food Technology, Faculty of Agro-Industry, Prince of Songkla University, Hat Yai, Songkhla 90110, Thailand. 'Department of Material Product Technology, Faculty of Agro-Industry, Prince of Songkla University, Hat Yai, Songkhla 90110, Thailand.
}

Published online: 09 December 2019

\section{Reference}

Singh, A., et al. (2019). Chitooligosaccharides from squid pen prepared using different enzymes: characteristics and the effect on quality of surimi gel during refrigerated storage. Food Production, Processing and Nutrition, 1, 5 https://doi.org/10.1186/s43014-019-0005-4.

Full list of author information is available at the end of the article 